\title{
Animasi Cerita Bangsawan Puteri Saadong: Adaptasi Teks dan Persembahan
}

\author{
${ }^{1}$ NUR YUHANIS BINTI MOHD. NASIR \\ ${ }^{2}$ RAHMAH BINTI BUJANG \\ ${ }^{3}$ EIZAN MAT HUSSAIN
}

\author{
Akademi Pengajian Melayu, Universiti Malaya, 50603 Kuala Lumpur, Malaysia. \\ 1yuhanis83@um.edu.my, ${ }^{2} r a h m a h @ u m . e d u . m y,{ }^{3 i z a h \_0286 @ y a h o o . c o m ~}$
}

\begin{abstract}
Abstrak Artikel ini membincangkan kerja pembangunan animasi dua dimensi (2D) ala persembahan Bangsawan. Tatakerja yang terlibat adalah adaptasi kisah legenda Puteri Saadong yang dipetik dari teks sastera tradisional Melayu bertajuk Hikayat Seri Kelantan dan pemahaman terhadap seni persembahan tradisional Bangsawan. Animasi yang dibangunkan menerusi kajian ini dinamakan Bangsawan Puteri Saadong seterusnya digunakan sebagai alat penilaian untuk melihat penerimaan penonton (responden) terhadap hasil adaptasi. Penilaian dilakukan secara kualitatif dan kuantitatif deskriptif. Dapatan kajian ini menunjukkan bahawa faktor peribadi seperti minat, umur, jantina dan latar belakang pendidikan mempengaruhi persepsi individu terhadap hasil adaptasi. Selain daripada itu, kajian ini juga menunjukkan bahawa animasi merupakan satu medium adaptasi yang sesuai dalam mempersembahkan kandungan lama atau bersejarah untuk dinikmati oleh generasi muda.
\end{abstract}

Kata kunci: Animasi, adaptasi, Bangsawan, Hikayat Seri Kelantan, Puteri Saadong

Abstract This paper discusses the work of a research in constructing a $2 D$ animation which depicts the Bangsawan theatre. The work process involves an adaptation of a story of the legendary Malay princess of yesteryear, Puteri Saadong as written in a Malay historical source of Hikayat Seri Kelantan and with good understanding of the Bangsawan live theatre phenomenon. The animation being developed is named 'Bangsawan Puteri Saadong' which later acts as a tool for the evalution of viewers' acceptance and being done in a mix-mode of qualitative and descriptive quantitative. The findings show that personal factors as interest, age, gender and educational background influence how a viewer perceives an adaptation work. Other than that, this 
research shows that animation is a medium that is great to present and recreate old information or story to reach younger generation.

Keywords: Animation, adaptation, Bangsawan, Hikayat Seri Kelantan, Puteri Saadong

\section{PENGENALAN}

Animasi telah membentuk satu industri kreatif. Di Malaysia, perkembangan dari segi teknologi dan tenaga mahir yang mempunyai daya artistik membawa kepada kemajuan industri animasi tempatan menembusi pasaran antarabangsa. Dengan sokongan daripada pihak kerajaan, penubuhan Koridor Raya Multimedia (Multimedia Super Corridor-MSC) telah mengelompokkan organisasi dan syarikat pembangunan multimedia kreatif termasuk animasi di bawah satu payung untuk terus memajukan industri kreatif Malaysia (Fadli \& Md Sidin, 2010: 69-82). Dalam pada itu, dasar industri kreatif negara juga diwujudkan bagi memberi bantuan dari segi dana dan sokongan lain kepada pihak yang terlibat dengan pembangunan kandungan kreatif yang dilihat mempunyai potensi bukan sahaja dari aspek janaan ekonomi negara, malah dalam melestarikan budaya bangsa (Industri Kreatif Negara, 2013). Penyediaan tenaga mahir turut diusahakan di peringkat pengajian bagi memupuk minat dan membentuk kemahiran generasi muda untuk penglibatan masa akan datang dalam industri ini.

Dalam artikel ini, penulis meneliti kreativiti animasi dalam teknologi multimedia. Aspek-aspek ini seterusnya dimanfaatkan dalam bidang Pengajian Melayu yang luas dengan pelbagai spektrum mencakupi ilmu sastera, seni, bahasa dan budaya. Kepentingan elemen cerita dalam karya animasi merupakan keperluan asas dalam pembangunannya. Secara am, cerita boleh disampaikan dengan pelbagai cara seperti lisan, teks bacaan dan paparan audio visual. Sejarah telah membuktikan peranan besar cerita dalam segenap lapisan masyarakat di seluruh dunia yang bertindak sebagai perantara untuk membekalkan masyarakat dengan pelbagai pengetahuan serta pengalaman dan menjadi alat penting dalam bidang sejarah, politik dan keagamaan (Forster et al., 1999: 11-17). Selaras dengan perkembangan 
tamadun manusia, pelbagai teknologi diperkenalkan hasil dari intelek manusia sendiri, lantas membawa banyak perubahan bagaimana cerita dihasil dan disampaikan.

\section{SOROTAN KAJIAN}

Para sarjana dari dalam dan luar negara banyak melakukan kajian multidisiplin antara bidang ilmu tradisi dan teknologi moden. Antara bidang yang menjadi fokus adalah keberkesanan serta penerimaan masyarakat semasa terhadap persembahan maklumat lama dalam format baharu menerusi kerja adaptasi. Dalam kajian oleh Mohd Izani dan Aishah (2003), satu produk dalam bentuk animasi cerita tiga dimensi (3D) dibangunkan untuk tujuan penilaian keberkesanan penyampaian cerita rakyat Melayu tradisional menerusi perisian digital interaktif. Fokus utama kajian lebih berorientasikan pendidikan menggunakan bahan multimedia. Penekanannya adalah terhadap elemen animasi sebagai medium penyampai yang berkonsepkan budaya tradisional.

Nor Azan, Nur Yuhanis dan Munirah (2010) melakukan kajian yang hampir sama melibatkan kerja pembangunan sebuah perisian animasi interaktif bernama MyEdutale untuk menyampaikan cerita rakyat Melayu. Kajian ini menggunakan teknologi animasi 2D dan menggunakan beberapa pendekatan dalam penyampaian cerita beranimasi antaranya menerusi syair dan peribahasa. MyEdutale seterusnya digunakan sebagai alat penilaian kebolehgunaan (usability) dan dapatan yang diperoleh menunjukkan penerimaan positif para pengguna terhadap penyampaian cerita rakyat berasaskan perisian digital interaktif dan animasi.

Rall (2011) dalam kajian beliau berpendapat bahawa masyarakat di negara Asia tidak banyak mengetengahkan nilai tradisional serta budaya masyarakat tersendiri dalam bentuk animasi walaupun mempunyai kepelbagaian bentuk kesenian tradisional. Dalam kajian beliau, enam mitos dari negara Asia dipilih dan dibangunkan dalam bentuk animasi dengan menerapkan elemen lokal serta falsafah estetika dalam reka bentuk animasi bagi mencerminkan asal usul setiap cerita. Kerja pembangunan animasi melibatkan beberapa kumpulan pembangun yang berasal dari beberapa 
negara Asia. Kajian yang dilakukan ini mendapati bahawa animasi yang berteraskan cerita tradisional sesebuah masyarakat mempunyai potensi untuk dimajukan tanpa perlu meniru gaya animasi yang sudah diiktiraf dunia seperti gaya anime dari Jepun dan gaya animasi Hollywood.

Yapp (2007) dalam kajian beliau membuat adaptasi sebuah cerita legenda dan membangunkan cerita tersebut dalam bentuk animasi 2D. Legenda yang dipilih untuk adaptasi berasal dari negeri Sarawak, iaitu 'Rentap' dan dibuat dengan tujuan untuk memahami identiti serta motivasi Rentap sebagai seorang tokoh legenda etnik Iban. Kajian menggunakan teori adaptasi Naremore dan merujuk konsep realisme dan statistik untuk pembangunan animasi cerita kajian.

Kajian oleh Kangong (2010) membuat tinjauan kes dengan menggunakan sebuah animasi cerita 3D bertajuk Magic Cellar sebagai bahan kajian. Kangong menggunakan animasi cerita tersebut untuk menilai kandungan cerita dari pelbagai aspek yang mewakili masyarakat Afrika Selatan yang merupakan sebuah komuniti majmuk. Dua persoalan utama kajian adalah bagaimana animasi 3D dapat digunakan sebagai medium pendidikan dan bagaimana animasi 3D dapat dimanfaatkan untuk menyampaikan mesej berkaitan tradisi serta budaya kepada masyarakat, khususnya di Afrika Selatan. Menerusi kajian ini, Kangong membuat kesimpulan bahawa animasi 3D merupakan satu medium yang bukan sahaja mampu menarik perhatian dan meningkatkan motivasi untuk belajar, tetapi juga dapat digunakan untuk menyampaikan kandungan yang memaparkan kepelbagaian budaya warisan sesebuah masyarakat.

Selain kajian lepas berkaitan animasi sebagai medium penyampai cerita bergenre tradisional, beberapa kajian berkaitan adaptasi turut dirujuk. Kajian oleh Anyanwu (2010) melakukan adaptasi teks; dari novel ke pentas atas kesedaran pengkaji terhadap isu tradisi bercerita dan persembahan teater yang semakin kurang diminati oleh masyarakat moden, khususnya dalam kalangan etnik Igbo di Nigeria. Dengan menggunakan pendekatan adaptasi Hutcheon (2006), adaptasi teks yang dilakukan Anyanwu menerapkan unsur budaya dalam pembinaan skrip yang ditulis untuk pementasan. Pengkaji 
seterusnya mengadakan dua sesi persembahan teater untuk mendapatkan respons penonton terhadap hasil adaptasi yang dilakukan dan dapatan yang diperoleh menunjukkan penerimaan yang memberangsangkan. Selaras dengan teori adaptasi (Hutcheon, 2006), penerimaan penonton serta para pelakon teater yang terlibat terhadap adaptasi teks yang dilakukan Anyanwu menunjukkan bahawa majoriti daripada mereka menerima intepretasi cerita pengkaji sebagai satu karya kreatif baharu memandangkan kebanyakannya tidak pernah membaca teks asal.

Kajian lain berkaitan adaptasi dari satu bentuk atau format ke bentuk atau format yang lain menunjukkan bahawa adaptasi melibatkan beberapa aktiviti kreatif yang membolehkan pengadaptasi berkarya mengikut kreativiti sendiri dan penikmat cerita (sama ada penonton atau pembaca) menerima hasil adaptasi sebagai satu karya baharu (Chiew, 2007). Secara perbandingan, kajian Rall lebih hampir kepada kajian yang dibincangkan dalam artikel ini memandangkan Rall (2011) menekankan transformasi cerita tradisional ke format animasi tanpa mengabaikan elemen yang mencerminkan budaya masyarakat. Kajian Anyanwu (2010) juga dekat dengan kajian ini memandangkan kedua-dua kajian melakukan adaptasi cerita sedia ada, membina skrip cerita adaptasi, melakukan adaptasi cerita pada medium baharu, (Anyanwu memilih media pentas, manakala kajian ini memilih animasi) dan terakhir, melakukan tinjauan persepsi terhadap hasil adaptasi kajian.

\section{LATAR BELAKANG KAJIAN}

Kemajuan dalam teknologi telah membawa pelbagai perubahan terhadap kehidupan masyarakat masa kini yang dengan jelas banyak dipengaruhi oleh teknologi. Sebagai contoh, penggunaan projektor dan komputer dalam kelas menggantikan papan hitam atau papan putih, kad ucapan dihantar secara digital menerusi e-mel atau e-kad, urusan bank secara atas talian dan lain-lain. Landskap dunia hiburan turut terkesan dengan perubahan ini apabila persembahan secara langsung seperti wayang kulit, makyung dan Bangsawan bukan lagi menjadi pilihan tunggal untuk masyarakat menikmati hiburan. Teknologi semasa memperkenalkan beberapa alternatif 
untuk pembangunan bahan hiburan, pada masa yang sama membolehkan masyarakat menikmatinya secara digital melalui medium seperti televisyen, panggung wayang dan atas talian.

Teknologi perkomputeran turut memperkenalkan animasi digital. Animasi atau kartun menjadi satu entiti penting dalam industri hiburan dan perfileman. Sebelum ini, Amerika Syarikat dan Jepun menjadi negara pengeluar animasi utama dunia dan Malaysia banyak mengimport animasi cerita dari negara tersebut. Namun, beberapa tahun kebelakangan ini, industri animasi Malaysia semakin maju dan banyak produk animasi tempatan yang dihasilkan. Hal ini dapat dilihat menerusi siri dan filem animasi 'Upin dan Ipin' dan 'Boboiboy.' Dengan penghasilan animasi cerita oleh syarikat tempatan, pengisian kandungan animasi lebih terarah kepada imej lokal.

Kajian ini menyedari potensi untuk mempersembahkan sesuatu yang bersifat tradisional ke suatu format moden. Menerusi adaptasi, cerita Melayu tradisional yang dipetik dari sebuah manuskrip Melayu lama dipersembahkan sebagai satu bahan tontonan dalam format animasi. Pada masa yang sama, penerapan elemen Melayu tradisional akan lebih menonjolkan nilai-nilai tradisi dalam cerita yang diadaptasi, maka kajian ini memilih untuk mempersembahkan animasi kajian mengikut gaya persembahan Bangsawan.

Bangsawan adalah satu bentuk teater tradisional Melayu yang popular sekitar tahun 1902 hingga 1935 (Nur Nina, 1992). Walau bagaimanapun, populariti Bangsawan sebagai hiburan dalam kalangan masyarakat di Tanah Melayu mulai pudar apabila perang dunia kedua dan penaklukan tentera Jepun ke atas Tanah Melayu (Nur Nina, 1992; Tan, 1993). Usaha untuk menggemilangkan semula Bangsawan sebagai satu bentuk seni warisan masyarakat Melayu giat dilakukan oleh beberapa pihak, antaranya dengan memperkenalkan Seri Semarak Bangsawan sejak tahun 2007 dan menyiarkan drama Bangsawan dalam bentuk siri televisyen (Nor Akmar, 2012). Adaptasi cerita yang dibuat dalam kajian ini adalah tentang Puteri Saadong yang dipetik dari Hikayat Seri Kelantan. Perbincangan seterusnya adalah berkenaan proses pembangunan animasi cerita ala Bangsawan dengan tajuk Bangsawan Puteri Saadong. 


\section{MODEL KAJIAN}

Visi kajian ini adalah membangunkan animasi multimedia dengan mengadaptasi teks dari sastera tradisional dan adaptasi persembahan bangsawan. Seterusnya, kajian ini memperincikan proses produksi animasi 2D ke atas adaptasi teks mengikut gaya persembahan Bangsawan dan menganalisis faktor yang mempengaruhi persepsi responden terhadap hasil animasi.

Perkara utama dan menjadi kemestian sewaktu membuat adaptasi adalah penyesuaian. Penyesuaian penting dalam adaptasi kerana melibatkan medium atau perantara yang berbeza. Medium ini dizahirkan pada media dan dalam konteks kajian ini, peralihan medium yang berlaku adalah dari media teks ke visual. Secara lebih spesifik, cerita asal adalah dalam bentuk bacaan dan disesuaikan ke bentuk animasi cerita. Dua teori yang digunakan dalam kajian ini adalah teori adaptasi Hutcheon (2006) dan persepsi visual Arnheim (1974). Pendekatan adaptasi yang diaplikasikan dalam menyesuaikan kisah Puteri Saadong dan persembahan bangsawan untuk pembangunan animasi kajian adalah pengekalan, pengguguran atau pengubahsuaian dan tokok tambah. Menurut Hutcheon (2006), penerimaan individu terhadap cerita adaptasi adalah berbeza dan dipengaruhi oleh faktor peribadi seperti jantina, umur, minat, latar belakang pendidikan serta pengalaman.

Bagi aspek pembangunan animasi Bangsawan Puteri Saadong, gabungan elemen multimedia seperti grafik, animasi dan audio menyempurnakan bentuk penyampaian kisah Puteri Saadong secara visual. Elemen cerita yang diolah mengikut gaya persembahan bangsawan disesuaikan dengan format animasi dan menurut Arnheim (1974), individu menanggap sesuatu yang dilihat secara bersama tanpa mengasingkan elemen yang membentuk suatu hasil kerja (seni). Tanggapan atau persepsi yang terbentuk adalah berbeza bagi setiap individu dan dipengaruhi oleh faktor peribadi. Hal ini merupakan satu titik temu antara teori persepsi visual Arnheim (1974) dan teori adaptasi Hutcheon (2006) yang menghasilkan model bagi kajian ini (rujuk Rajah 1). 


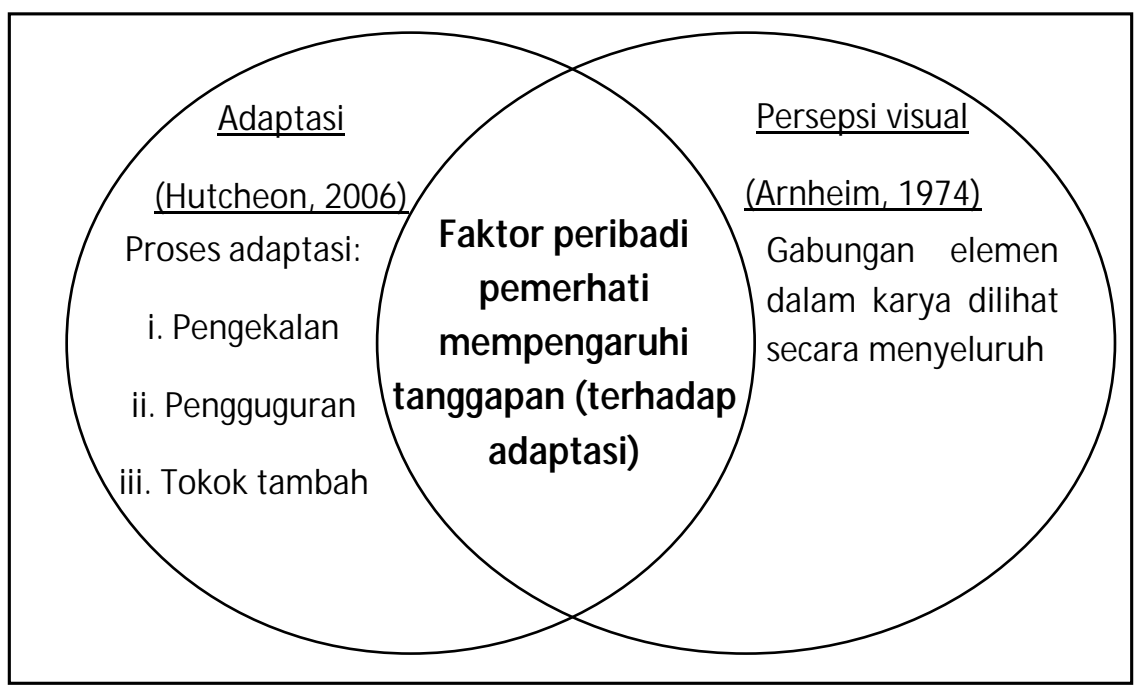

Rajah 1 Model kajian ini yang terhasil dari teori adaptasi (Hutcheon, 2006) dengan teori persepsi visual (Arnheim, 1974)

\section{PENULISAN SKRIP BANGSAWAN PUTERI SAADONG}

Dalam persembahan Bangsawan sebenar, sebuah cerita boleh dipersembahkan secara berepisod (Nur Nina, 1992). Dengan cara ini, fokus penonton terhadap cerita dapat dikekalkan. Animasi Bangsawan Puteri Saadong untuk kajian ini dihasilkan dalam 12 episod bagi membolehkan penonton menumpukan perhatian terhadap cerita yang dipersembahkan dan secara tidak langsung sebagai makluman bahawa sebuah cerita Bangsawan boleh dibuat secara berepisod.

Skrip Bangsawan Puteri Saadong adalah berdasarkan manuskrip Melayu lama, Hikayat Seri Kelantan yang ditulis dalam tulisan Jawi. Mohd Taib Osman telah menghasilkan satu versi transliterasi dari tulisan Jawi ke rumi pada tahun 1961 untuk kajian di peringkat sarjana yang kemudian telah diterbitkan dalam bentuk buku oleh Dewan Bahasa dan Pustaka pada tahun 2004.

Secara ringkas, Rajah 2 menunjukkan kronologi peristiwa penting yang mengisahkan Puteri Saadong. 


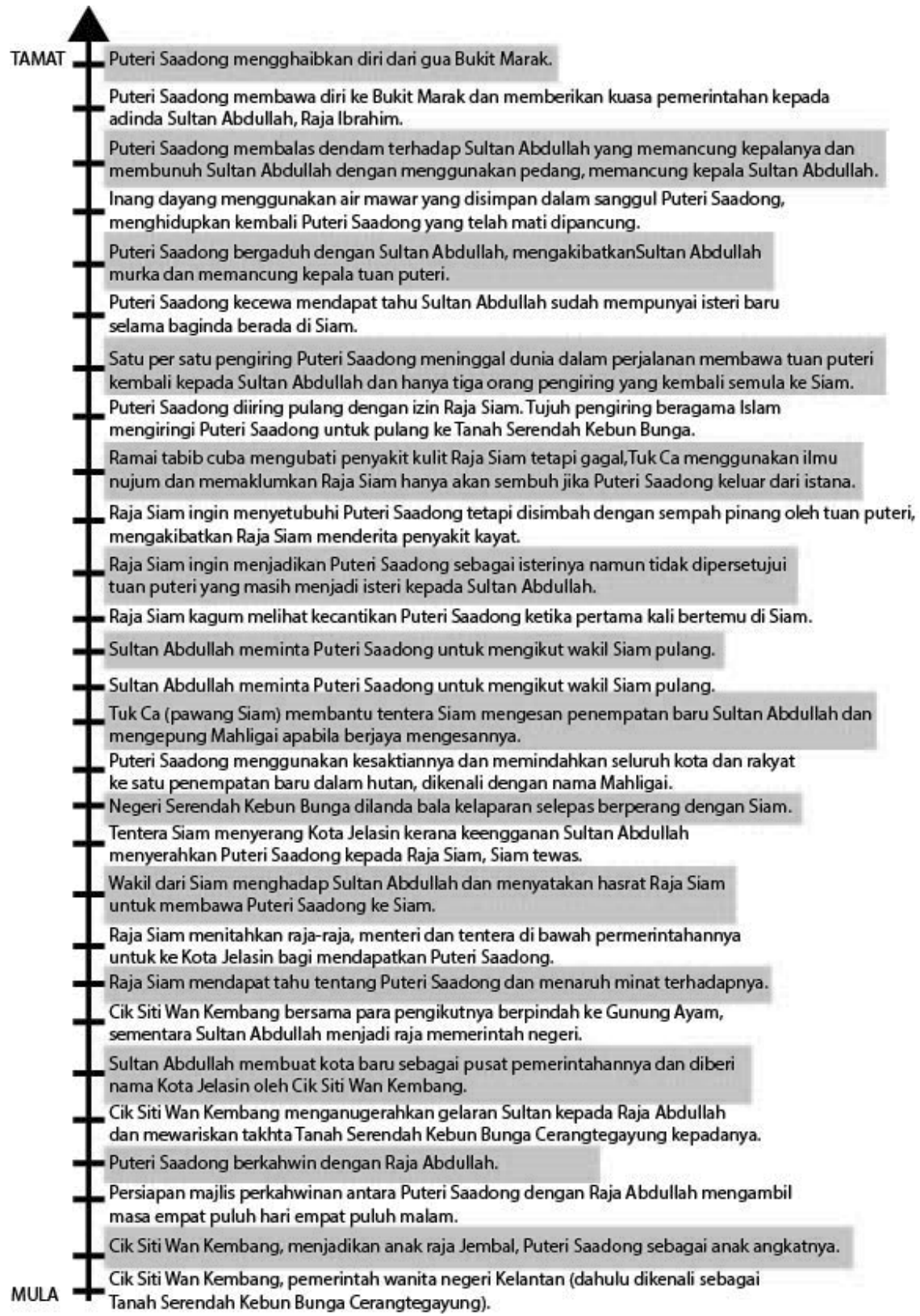

\section{Rajah 2 Kronologi peristiwa kisah Tuan Puteri Saadong menurut Hikayat Seri Kelantan}


Dalam adaptasi yang dilakukan untuk kajian ini, perubahan dilakukan ke atas cerita asal dengan cara berikut (Hutcheon, 2006):

i. Mengekalkan cerita asal.

ii. Menggugurkan maklumat yang kurang/tidak signifikan.

iii.Menokok tambah pada cerita asal.

Proses yang dilakukan ini menjadi norma dalam aktiviti adaptasi yang memerlukan penyesuaian terhadap medium adaptasi yang dipilih (Saputra, 2009; Stam, 2005).

Pengakhiran kisah Puteri Saadong yang diadaptasi dalam kajian ini adalah perjalanan pulang Puteri Saadong ke Kota Jelasin setelah dibebaskan oleh Raja Siam. Jika diteliti, kisah asal Puteri Saadong selepas bertemu semula dengan suaminya, Sultan Abdullah mengandungi banyak elemen ganas yang tidak menepati ajaran Islam mahupun moral masyarakat Melayu. Satu ciri dalam persembahan Bangsawan pula adalah cerita yang mempunyai nilai pengajaran positif dan poetic-justice (Nur Nina, 1992; Tan 1993). Bersesuaian dengan ciri ini, 'Bangsawan Puteri Saadong' ditulis untuk mempunyai penamat yang menggembirakan dan memberi gambaran penyatuan semula Puteri Saadong dengan suaminya.

\section{ANIMASI 'BANGSAWAN PUTERI SAADONG'}

Seni persembahan bangsawan diadaptasikan dalam animasi "Bangsawan Puteri Saadong” untuk menonjolkan identiti Melayu pada cerita yang diadaptasi daripada teks sastera tradisional. Penerapan elemen Melayu dibuat pada reka bentuk grafik, manipulasi grafik untuk animasi dan juga fail audio yang digunakan. Hasil akhir produk animasi kajian kemudian digunakan sebagai alat (tool) untuk menilai persepsi penonton (responden) terhadap adaptasi teks dan persembahan ke bentuk visual. Rajah 3 hingga Rajah 5 menunjukkan antara paparan skrin yang dibangunkan untuk animasi 'Bangsawan Puteri Saadong'. 


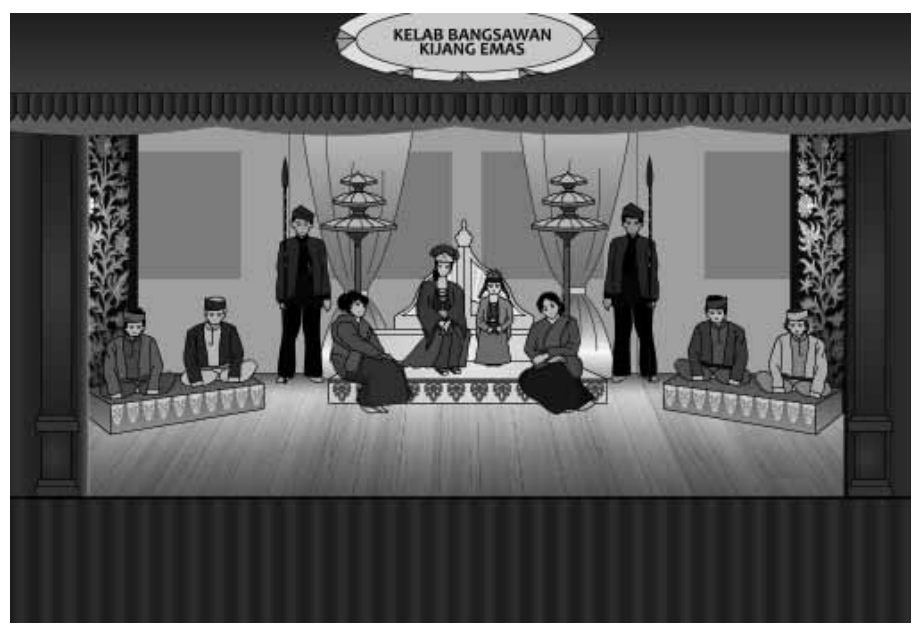

Rajah 3 Cetakan skrin dari Episod 1 animasi Bangsawan Puteri Saadong

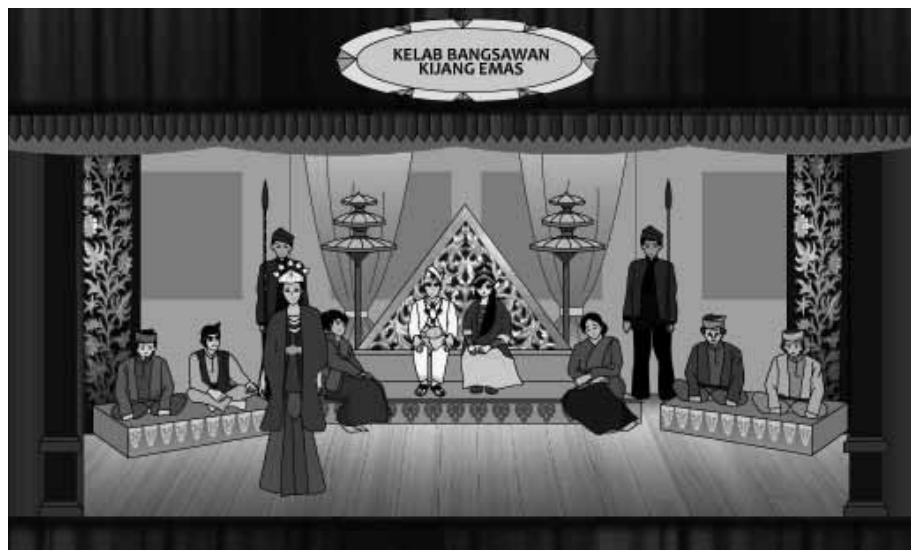

Rajah 4 Cetakan skrin dari Episod 3 animasi Bangsawan Puteri Saadong 


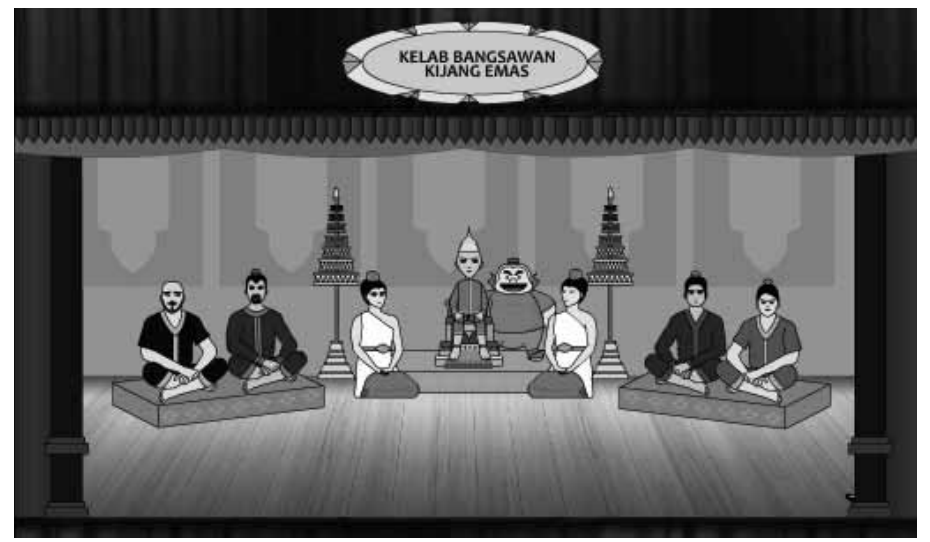

Rajah 5 Cetakan skrin dari Episod 8 animasi Bangsawan Puteri Saadong

\section{DAPATAN PENILAIAN ANIMASI BANGSAWAN PUTERI SAADONG}

Penilaian untuk kajian ini dilakukan secara kualitatif melalui kaedah temu bual dan pemerhatian. Sebagai sokongan kepada dapatan kualitatif, penilaian menggunakan borang soal selidik turut dibuat dan dianalisis secara kuantitatif deskriptif. Gabungan antara kaedah kualitatif dan kuantitatif dalam kajian mampu memberikan dapatan yang lebih menyeluruh (Weinreich, 2006). Penilaian ini melibatkan 65 orang responden yang mempunyai latar belakang pendidikan berbeza dan julat umur di antara 19 hingga 55 tahun. Selain daripada itu, pandangan dua orang pakar bidang, iaitu seorang pensyarah bidang Sastera Melayu Tradisional (Manuskrip) dan seorang pensyarah bidang Seni Persembahan Melayu selaku informan turut diperoleh menerusi temu bual. Beberapa dapatan penting telah diperoleh dan dirumuskan seperti yang berikut:

- $\quad$ Minat individu pada suatu genre cerita mempengaruhi kemampuan serta usaha individu dalam memahami cerita. Dalam konteks kajian ini, bagi responden yang tidak berminat dengan genre sastera Melayu tradisional, pembacaan terhadap kisah Puteri Saadong dalam bentuk teks Hikayat Seri Kelantan adalah lebih sukar berbanding dengan responden yang mempunyai minat terhadap genre sastera Melayu tradisional. 
- Latar belakang pendidikan individu mempengaruhi penerimaan individu itu terhadap hasil adaptasi cerita. Dalam penilaian yang dilakukan, responden yang mempunyai latar belakang dalam bidang Pengajian Melayu (merangkumi disiplin seperti sastera, sosio budaya dan kesenian Melayu) menanggap bahawa animasi Bangsawan Puteri Saadong adalah berkonsepkan sebuah persembahan bangsawan. Bagi responden yang tidak mempunyai latar belakang pendidikan dalam bidang Pengajian Melayu, contohnya responden dari bidang Sains dan Pentadbiran, animasi Bangsawan Puteri Saadong ditanggap sebagai satu bentuk lakonan pentas.

- $\quad$ Pengalaman individu mempengaruhi persepsi responden terhadap hasil adaptasi cerita. Ada beberapa orang responden yang tidak mempunyai latar belakang pendidikan dalam bidang Pengajian Melayu tetapi pernah menonton persembahan bangsawan sebenar menanggap animasi Bangsawan Puteri Saadong dibangunkan dengan konsep persembahan bangsawan. Persepsi ini terbentuk menerusi reka bentuk grafik pentas seperti bingkai, mempunyai tirai buka-tutup dan lain-lain props yang dikatakan menyerupai bentuk asas persembahan bangsawan sebenar.

Bagi dua orang informan yang ditemu bual, banyak pendapat dan komen diberikan terhadap animasi Bangsawan Puteri Saadong yang mana informan pertama (pakar bidang sastera tradisional) bersetuju dengan penerapan ciri-ciri Melayu tradisional dalam adaptasi yang dihasilkan. Penyampaian cerita menerusi syair, pantun serta bahasa Melayu klasik menerusi penggunaan bahasa istana untuk dialog dilihat membentuk identiti Melayu dalam animasi cerita kajian. Selain daripada itu, informan pertama berpendapat pengekalan maklumat asal lebih sesuai untuk adaptasi sastera tradisional seperti yang diamalkan dalam proses adaptasi kajian ini. Adaptasi yang terlalu banyak mengubah cerita asal dirasakan akan mengakibatkan banyak maklumat bersejarah hilang.

Bagi informan kedua (pakar bidang seni persembahan), komen terhadap aspek seni lebih banyak diberikan. Pada pandangan beliau, animasi Bangsawan Puteri Saadong akan lebih menarik jika pembinaan cerita tertumpu dan menekankan watak utama, iaitu Puteri Saadong berbanding dengan elemen cerita seperti yang dilakukan dalam kajian ini. 
Malahan, sebagai seorang yang berpengalaman dalam seni persembahan bangsawan, informan kedua lebih teliti dalam menilai animasi kajian dari perspektif seni.

- $\quad$ Adaptasi cerita dari genre sastera Melayu tradisional ke animasi cerita mampu meningkatkan kefahaman individu terhadap cerita lama. Tidak semua responden dapat memahami kisah Puteri Saadong dalam format asal, iaitu teks yang ditulis menggunakan bahasa Melayu klasik dengan dialek negeri Kelantan. Namun, apabila adaptasi dilakukan, perubahan dari segi medium persembahan dari teks ke animasi cerita menuntut kerja penyesuaian. Dalam animasi Bangsawan Puteri Saadong, penyampaian cerita disasarkan bukan untuk tujuan bacaan tetapi untuk tujuan tontonan. Maka, gabungan elemen multimedia iaitu grafik, animasi, teks dan audio dalam mempersembahkan kisah Puteri Saadong membantu kefahaman responden selaku penonton. Selain daripada itu, penceritaan menggunakan dialog antara watak turut memudahkan penyampaian cerita.

- $\quad$ Genre sastera Melayu tradisional sesuai dan dapat diterima sebagai sumber adaptasi cerita ke format animasi. Menerusi penilaian yang dilakukan, peratusan responden yang setuju dengan genre sastera tradisional sebagai sumber adaptasi ke bentuk animasi adalah 73 peratus. Hal ini menunjukkan bahawa potensi untuk memaju serta mengembangkan sastera tradisional dalam bentuk animasi adalah cukup besar.

- $\quad$ Adaptasi persembahan Melayu tradisional (dalam konteks kajian ini adalah seni persembahan bangsawan) ke format animasi cerita mengukuhkan ciri-ciri Melayu pada cerita adaptasi teks. Seni persembahan bangsawan mempunyai ciri-ciri unik yang membentuk identiti kesenian tersebut sebagai satu warisan budaya Melayu. Dengan suntikan ciri persembahan bangsawan dalam kisah Puteri Saadong yang diadaptasi dari teks, animasi Bangsawan Puteri Saadong dibangunkan seperti satu bentuk lakonan bangsawan secara digital.

- Selain daripada minat, latar belakang pendidikan dan pengalaman, persepsi individu terhadap hasil adaptasi cerita turut dipengaruhi oleh faktor jantina dan umur. Hal ini dilihat dari segi pilihan episod oleh responden. 
Kebanyakan responden yang memilih episod dengan adegan aksi adalah lelaki. Responden wanita pula lebih suka pada melodrama yang memaparkan kasih sayang antara Puteri Saadong dengan suaminya dan pengakhiran cerita yang bahagia atau happy ending. Dari segi umur, golongan yang lebih dewasa yang berusia 30 tahun ke atas lebih menghargai persembahan cerita yang mengandungi nilai sejarah, manakala golongan muda menanggap pada elemen penceritaan bersifat hiburan.

\section{KESIMPULAN}

Media dan teknologi moden menyediakan alternatif untuk mempersembahkan sesuatu yang lama seperti cerita dan kesenian budaya dalam bentuk baharu. Hal ini membuka ruang untuk khazanah serta warisan masyarakat yang semakin dilupakan untuk disampaikan kepada masyarakat masa kini yang serba-serbi dipengaruhi oleh teknologi digital. Dengan memanfaatkan teknologi animasi komputer, kajian ini membuat adaptasi cerita dari sebuah teks Melayu lama dan juga adaptasi seni persembahan Bangsawan bagi membangunkan kisah Puteri Saadong dalam format animasi 2D. Pemilihan seni persembahan Bangsawan sebagai gaya persembahan animasi yang dibina memberi sentuhan Melayu tradisional terhadap cerita yang diadaptasikan.

Walaupun karya adaptasi tidak berhutang pada sumber adaptasi (Hutcheon, 2006) yang membolehkan pengadaptasi berkarya mengikut kreativiti sendiri, teks yang mempunyai nilai sejarah perlu mengekalkan nilai budaya dalam pembinaan cerita baharu. Mempersembahkan tradisi lama dalam bentuk baharu menerusi pelbagai pilihan media dan teknologi baharu membuka lebih banyak kemungkinan penerimaan masyarakat masa kini terhadap warisan budaya dahulu.

Menerusi kajian yang dilakukan ini, dapat dinyatakan bahawa aplikasi pendekatan adaptasi Hutcheon (2006) membolehkan cerita dari genre sastera tradisional disesuaikan untuk penyampaian cerita pada medium visual seperti animasi cerita. Berdasarkan persepsi visual Arnheim (1974) pula, ternyata penggunaan pelbagai elemen multimedia yang menyokong 
elemen cerita dalam animasi membentuk satu kesatuan pada cerita adaptasi yang dipersembahkan dalam format visual. Wujud kesinambungan antara setiap elemen yang menyokong antara satu sama lain.

Teks dan visual sememangnya mempunyai kelebihan dan kekurangan tersendiri. Namun, bagi masyarakat masa kini yang banyak dipengaruhi dengan teknologi digital, penyampaian maklumat atau cerita secara visual lebih mudah dan convenient. Dapatan kajian ini menunjukkan bahawa pemindahan karya daripada teks seperti sastera tradisional ke bentuk visual dengan teknologi multimedia perlu diusahakan dengan lebih padu supaya warisan budaya dapat dikembangkan dan sampai kepada masyarakat semasa. Namun pemindahan atau adaptasi yang dilakukan masih perlu mengekalkan elemen tradisional kerana itulah yang menjadi identiti kepada sesuatu bangsa. Perubahan pasti berlaku dalam melakukan adaptasi, namun pengadaptasi perlu peka dan sensitif apabila mengangkat sastera tradisional ke sesuatu format baharu.

\section{RUJUKAN}

Abdul Samat, S. (2006). Acting aspect in bangsawan theatre. Kuala Lumpur: KeKKWa.

Anyanwu, C. P. K. (2010). Adapting a man of the people to stage: Can stage adaptation successfully return Igbo literacy fiction to Igbo people?. (Tesis Doktor Falsafah). Middlesex University, London, United Kingdom.

Arnheim, R. (1974). Art and visual perception: A psychology of the creative eyew (New ed.). Berkeley: University of California Press.

Chiew, S. T. (2007). Chinese text, Western analysis: From film to novel. (Tesis Doktor Falsafah). University of Glasgow, Scotland, United Kingdom.

Cunningham, M. (n.d.). How to write plot for fiction. Dilayari daripada http:// solqushorts.com/our-how-to-section/how-to-write-plot-for-fiction/

Fadli Abdullah \& Md Sidin Ahmad Ishak. (2010). Pembangunan sektor animasi di Malaysia: Pendidikan dan latihan animasi di institusi pengajian tinggi awam. Malaysian Journal of Media Studies, 12 (2): pp. 69-82.

Forster, N., Cebis, M., Majteles, S., Mathur, A., Motgan, R., Preuss, J., Tiwari, V, Wilkinson, D. (1999). The role of story-telling in organizational leadership. Leadership \& Organization Development Journal, 20 (1), pp. 11-17.

Freytag, G. (1968). Technique of the drama; An exposition of dramatic composition and art. New York: B. Blom. 
Hatcher, J. (1996). The art \& craft of playwriting. Ohio: Story Press.

Hutcheon, L. (2006). A theory of adaptation. New York: Routledge.

Industri Kreatif Negara. (2013). Pengenalan Dasar Industri Kreatif Negara. Capaian http://www.industrikreatif.gov.my/industri-kreatif.

Jamaluddin, H., \& Zaidatun, T. (2005). Animasi: Dari helaian kertas ke skrin digital. Kuala Lumpur: Venton Publishing.

Kangong, R. N. (2010). 3D animation as a medium of cultural representation and education: A case study of Magic Cellar Part 1 (Tesis Sarjana). University of the Witwatersrand, Johannesburg, South Africa.

Mohd Izani, Z. A. \& Aishah, A. R. (2003). Malay digital folklore: Using multimedia to educate children through storytelling. 'Information technology in Childhood Education Annual, 1(2003): pp. 29-44.

Mohd Taib Osman. (1961). Hikayat Seri Kelantan: Sa-buah naskhah tulisan tangan dari Kelantan (Tesis Sarjana). Universiti Malaya, Kuala Lumpur, Malaysia.

Mohd Taib Osman. (2004). Hikayat Seri Kelantan. Kuala Lumpur: Dewan Bahasa dan Pustaka.

Nor Akmar Samudin (2012, 14 Jun). JKKN cuba selamat bangsawan. Harian Metro. Dilayari daripada http://www2.hmetro.com.my/articles/ JKKNcubaselamatbangsawan/Article/

Nor Azan Mat Zin, Nur Yuhanis Mohd Nasir \& Munirah Ghazali. (2010). Promoting Socio-cultural values through storytelling using animation and gamebased edutainment software. In M. Crisan (Ed.), Convergence and Hybrid Information Technologies (pp. 210-227).

Nur Nina, Z. (1992). An analysis of modern Malay drama. Shah Alam: Biroteks.

Parker, W. O. (2009). Scene design and stage lighting ( $9^{\text {th }}$ ed.). Belmont: Wadsworth Cengage Learning.

Rahmah Bujang. (1994). Drama Melayu: Dari skrip ke pentas. Kuala Lumpur: Dewan Bahasa dan Pustaka.

Rahmah Bujang. (2007). Wadah wahana seni persembahan. Kuala Lumpur: Jabatan Penerbitan Akademi Pengajian Melayu, Universiti Malaya.

Rall, H. (2011). Tradigital mythmaking: New Asian design ideas for animation. Animation Studies 6: pp. 14-25.

Saputra, H. S. P. (2009). Transformasi lintas genre: Dari novel ke film, dari film ke novel. Humaniora, 21: pp. 41-55.

Sharma, S. (2012). Indian folktales get animated twist. The Sunday Guardian, [cited 29 July 2012]. Dilayari daripada http://www.sunday-guardian.com/artbeat/ indian-folktales-get-animated-twist

Stam, R. (2005). Introduction: The theory and practice of adaptation. Dlm. Stam. R. \& Raengo Alessandra (Eds.), Literature and Film (pp. 1-54). Victoria: Blackwell Publishing. 
Tan, S. B. (1993). Bangsawan: A social and stylistic history of popular Malay opera. Singapore: Oxford University Press.

Wyatt, A. (2010). The complete digital animation course: Principles, practice and techniques: A practical guide for aspiring animators. New York: Hauppauge.

Weinreich, N. K. (2006). Integrating Quantitative and Qualitative Methods in Social Marketing. Dilayari daripada http://www.social-marketing.com/ research.html.

Yapp, A. (2007). Rentap: Adaptasi cerita legenda ke dalam bentuk animasi 2 dimensi (Tesis Sarjana). Universiti Malaysia Sarawak, Sarawak, Malaysia. 